\title{
Durability Assessment of GFRP Rebars Exposed to High pH-Seawater
}

\author{
Alvaro Ruiz Emparanza ${ }^{1}$, Carlos N. Morales $^{2}$, Juan Manuel Palacios ${ }^{3}$, Francisco De \\ $\mathrm{Caso}^{4}$, and Antonio Nanni ${ }^{5}$ \\ ${ }^{1}$ University of Miami, College of Engineering, Dept. of Civil Architectural and Environmental \\ Engineering, 1251 Memorial Dr, Coral Gables, FL 33146, alvaro.ruiz@miami.edu \\ ${ }^{2}$ University of Miami, College of Engineering, Dept. of Civil Architectural and Environmental \\ Engineering, 1251 Memorial Dr, Coral Gables, FL 33146, cnm32@miami.edu \\ ${ }^{3}$ University of Miami, College of Engineering, Dept. of Civil Architectural and Environmental \\ Engineering, 1251 Memorial Dr, Coral Gables, FL 33146, jxp1698@miami.edu \\ ${ }^{4}$ University of Miami, College of Engineering, Dept. of Civil Architectural and Environmental \\ Engineering, 1251 Memorial Dr, Coral Gables, FL 33146, fdecaso@miami.edu \\ ${ }^{5}$ University of Miami, College of Engineering, Dept. of Civil Architectural and Environmental \\ Engineering, 1251 Memorial Dr, Coral Gables, FL 33146, nanni@miami.edu
}

\begin{abstract}
There is a continued process to implement innovative materials to enhance the sustainability and durability of the built infrastructure. Technologies developed over the last two decades have facilitated the use of glass fiber reinforced polymer (GFRP) composites as internal reinforcement bars (rebars) for concrete structures, which have proven to be an alternative to traditional steel reinforcement due to significant advantages, such as magnetic transparency and, most importantly, corrosion resistance, equating to durability and structural life extension. This study evaluates the durability of three different available and most commonly used GFRP rebar types, based on exposure to aggressive environments, such as those experienced in coastal areas. For that, the specimens were expose to high $\mathrm{pH}$ seawater solution (that simulates the alkalinity of the concrete exposed to seawater), at $60{ }^{\circ} \mathrm{C}$ for different periods of time: 45, 90, and 180 days. The durability of these GFRP rebars was assessed by testing four different physio-mechanical properties, including: tensile strength, elastic modulus, and transverse and horizontal shear strength. Preliminary results show that the resilience of the GFRP rebars after being exposed to high $\mathrm{pH}$ seawater at high temperature, varies considerably among the three different types. The tensile strength was the most affected physio-mechanical property.
\end{abstract}

Keywords: Composites, Durability, GFRP Rebars, Resilience.

\section{Introduction}

The use of GFRP bars (Glass Fiber Reinforced Polymer) is gaining importance as internal reinforcement for reinforced concrete (RC) structures, primarily due to the corrosion-resistant properties. One of the most important applications for this alternative reinforcement is its use in coastal RC structures where corrosion of traditional steel rebars is critical (Nolan, Rossini and Nanni, 2018) and poses significant issues for the longevity and cost of the infrastructure. This is especially important in marine environments due to: i) salt water in direct contact with concrete structures, through foundations or by air and ii) the need to increase the infrastructure's future resilience and sustainability to sustain the numerous effects related to climate change, such as the sea level rise. These critical needs may no longer be of concern with the use of 
GFRP bars; which are composite reinforcing bars made of glass fibers embedded in a resin matrix and are non-corrosive. Because the driving force for such alternative reinforcement bars is the lifespan extension of RC structures, the durability of GFRP rebars must be carefully evaluated, as these aspects are fundamental for the expansion and extended application of this technology.

Concrete is considered a highly alkaline material, with typical $\mathrm{pH}$ values for freshly placed concrete above 12.5 to 13.9 for concrete made with high alkaline cement (Grubb, Jennifer A., et al., 2007). When using steel reinforcement, the high alkalinity of the concrete provides corrosion protection to the steel by providing a passive layer of iron oxide $\left(\mathrm{Fe}_{2} \mathrm{O}_{3}\right)$. Throughout the service life of the reinforced concrete structures, different phenomena such as carbonation, ingress of corrosive agents through voids and cracks, etc. lead to the breakdown of this passive layer, favouring the corrosion of steel. With GFRP rebars, however, the high alkalinity of concrete does not have a protective effect as for the steel, but it appears to affects the durability of the rebars in a negative way instead.

In the literature, different studies exist that have proven the deterioration of the tensile properties of GFRP rebars embedded in concrete or subjected to high $\mathrm{pH}$ solutions which simulate the alkalinity of the concrete, through accelerated aging protocols (Dejke and Tepfers, 2001; Chen, Davalos and Ray, 2006; Robert, Cousin and Benmokrane, 2009; Robert and Benmokrane, 2013; Wang, X.-L. Zhao, et al., 2017). In addition, Wang et al. (2017) evaluated the effect of the simulated seawater and sea sand concrete on the horizontal shear properties of GFRP rebars, while Ruiz Emparanza et al. (2018) Yan et al (2017) and Dong et al. (2016) assessed the resilience of bond properties of GFRP rebats embedded in concrete and exposed
to seawater. Each of these studies are focused on the resilience of a single mechanical prope ty,
and to the best knowlddge of the author, po rescareh exists that integrates a combined durability
unsessment of different mechanical characteristics, which would help to have a petter

Therefore, this study is comprised by the evaluation of the durability of three different

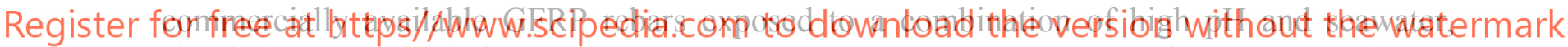
simulating coastal reinforced concrete structures. The rebars were aged for up to 180 days at $60^{\circ} \mathrm{C}$ to accelerate the degradation process. High temperature is used since it is expected that the rate of reaction will double every $10^{\circ} \mathrm{C}$ (Pauling 1988). A temperature of $60^{\circ} \mathrm{C}$ was chosen based on the practices found in the literature (Dejke and Tepfers, 2001; Chen, Davalos and Ray, 2006; Robert, Cousin and Benmokrane, 2009; Robert and Benmokrane, 2013; Wang, X.-L. Zhao, et al., 2017). Four different mechanical properties were tested: tensile strength, modulus of elasticity, transverse shear strength and horizontal shear strength. 


\section{Experimental Program}

Three types of GFRP bars, denoted as A, B and C, were tested for comparison purposes due to diversity of the products in the GFRP rebar market (Ruiz Emparanza, Kampmann and De Caso Y Basalo, 2017). All tested bars in this study had a nominal diameter of 10-mm and were made of continuous EC-R glass fiber and impregnated with a vinyl ester resin. However, the manufacturing process and surface enhancements varied among them: Type-A bars were sandcoated, Type-B were helically wrapped, while Type-C were ribbed (see Figure 1).
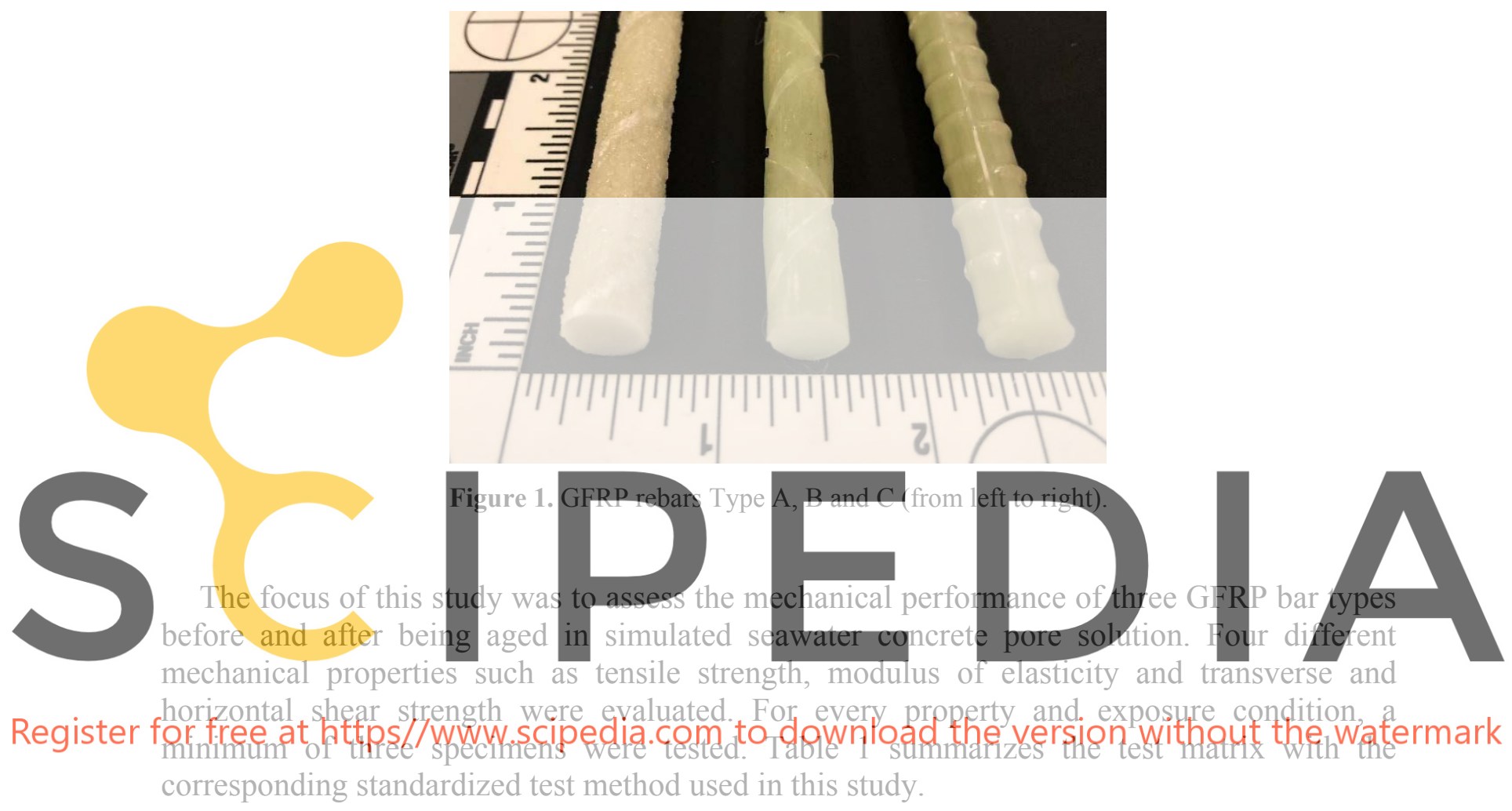

Table 1. Test Matrix for durability assessment.

\begin{tabular}{|c|c|c|c|c|}
\hline $\begin{array}{c}\text { Rebar } \\
\text { type }\end{array}$ & $\begin{array}{c}\text { Temp. } \\
{ }^{\circ} \mathrm{C} \\
\end{array}$ & $\begin{array}{c}\text { Duration } \\
\text { Days } \\
\end{array}$ & Mechanical Property & Test Method \\
\hline \multirow{3}{*}{$\begin{array}{l}\text { A } \\
\text { B } \\
\text { C }\end{array}$} & \multirow{3}{*}{60} & \multirow{3}{*}{$\begin{array}{c}45 \\
90 \\
180\end{array}$} & $\begin{array}{l}\text { Tensile Strength } \\
\text { Modulus of Elasticity }\end{array}$ & ASTM D7205 \\
\hline & & & Transverse Shear Strength & ASTM D7617 \\
\hline & & & Horizontal Shear Strength & ASTM D4475 \\
\hline
\end{tabular}

In addition to the tests run on specimens that were aged at $60{ }^{\circ} \mathrm{C}$ for 45,90 and 180 days as seen in Table 1, three repetitions per mechanical property were tested on non-exposed specimens. These results were used as benchmark to assess the resilience of the mechanical properties after the accelerated aging protocol. 


\subsection{Simulated Environmental Exposure Condition}

The accelerated aging of the GFRP bars specimens was achieved by completely immersing the bars into a to high $\mathrm{pH}$ seawater solution at $60^{\circ} \mathrm{C}$ and different exposure times $(45,90$ and 180 days). The seawater used was directly taken from Key Biscayne (Florida, USA). The solution was made by dissolving calcium hydroxide, sodium hydroxide and potassium hydroxide in seawater $\left(2 \mathrm{~g}\right.$ of $\mathrm{Ca}(\mathrm{OH})_{2}+2.4 \mathrm{~g}$ of $\mathrm{NaOH}+19.6 \mathrm{~g}$ of $\mathrm{KOH}$ per liter of seawater). The mass concentrations of the solution were chosen according to Chen et. al 2006 (Chen, Davalos and Ray, 2006). The high alkalinity solution simulates the pore solution of normal concrete with a $\mathrm{pH}$ value of about 13.6.

\subsection{Specimen Preparation}

After each exposure condition, the GFRP rebars were extracted from the solution and prepared for testing according to the corresponding ASTM standards. The preparation of the specimens used to test the transverse shear strength consisted of cutting the rebars to $230 \mathrm{~mm}$ specimens while the samples for horizontal shear were cut to a length of 6 times the diameter $(60 \mathrm{~mm})$. The preparation of the tensile samples to assess the ultimate tensile strength and modulus of elasticity, was more extensive: after the rebars were cut to length of $1000 \mathrm{~mm}$, protective anchors were installed at both ends of the samples to protect the rebar when being gripped by the loading machine. The anchorage system was accomplished by a $300 \mathrm{~mm}$ long steel pipe filled with expansive grout which will reduce lateral stresses during griping, since GFRP rebars are weak in the transver 2.3 Testing Procedure Each of the tests werd conducted in accordance are shown in Figure 2
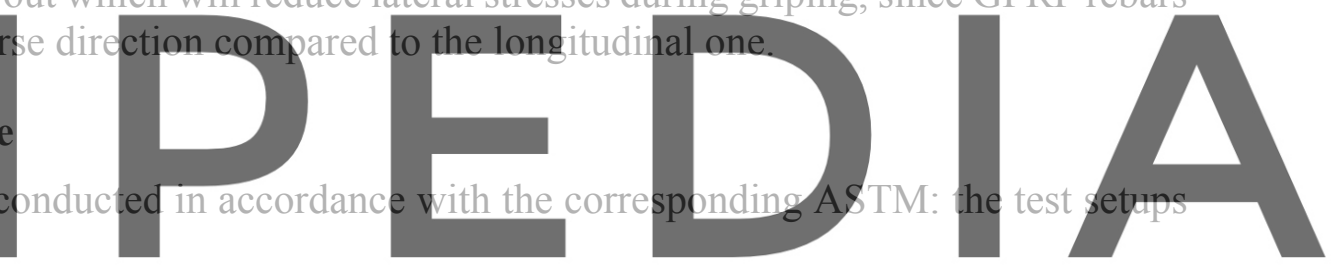

\section{Register for free at https//www.scipedia.com to download the version without the watermark}
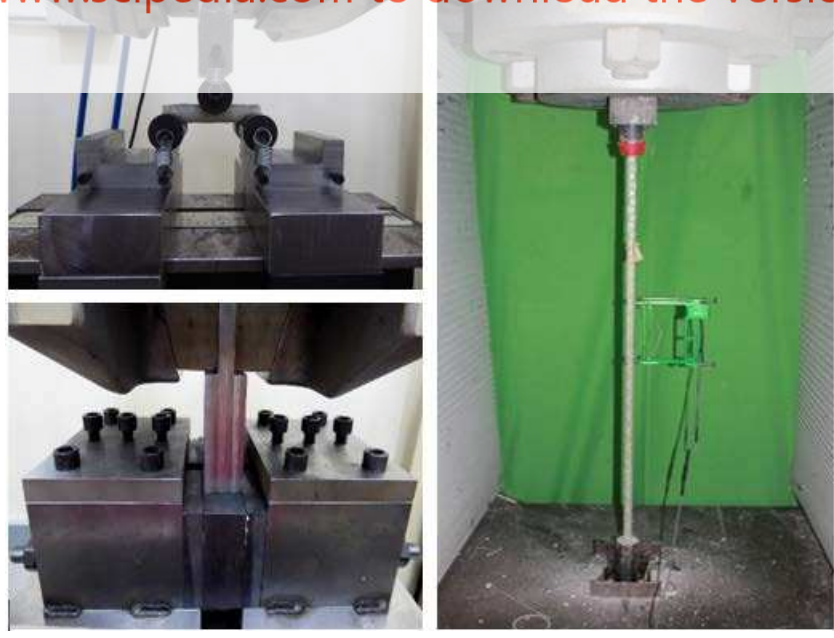

Figure 2. Test setup: horizontal shear test (top left), transverse shear test (bottom left), and tensile test (right).

In this study, all tests were performed by applying displacement-controlled loading using a Baldwin machine with a capacity of $890-\mathrm{kN}$ for the tensile test, and a $133-\mathrm{kN}$ Instron test frame 
for transverse and horizontal shear tests. The test rate for the tensile test was $2 \mathrm{~mm} / \mathrm{min}$, while for transverse and horizontal shear test specimens were tested at a rate of $1.3 \mathrm{~mm} / \mathrm{min}$. As per the corresponding ASTMs (see Table 1), for transverse and horizontal shear tests, the crosshead displacement and the load were recorded. For the tensile tests, in addition to the load, each of the specimens were instrumented with a $100 \mathrm{~mm}$ long extensometer to record the strain, which was then used to determine the modulus of elasticity.

\section{Results and Discussion}

For the three different types of rebars within the scope of this research project, four mechanical properties of unaged and aged specimens were evaluated.

\subsection{Unaged Samples}

The mechanical properties for 'as-received' GFRP bars used in this study are summarized in Table 2. Mechanical characterization of pristine GFRP bars provided unconditioned values as a reference for residual strength after exposure.

Table 2. Nominal mechanical properties of $10 \mathrm{~mm}$ diameter reference GFRP bars.

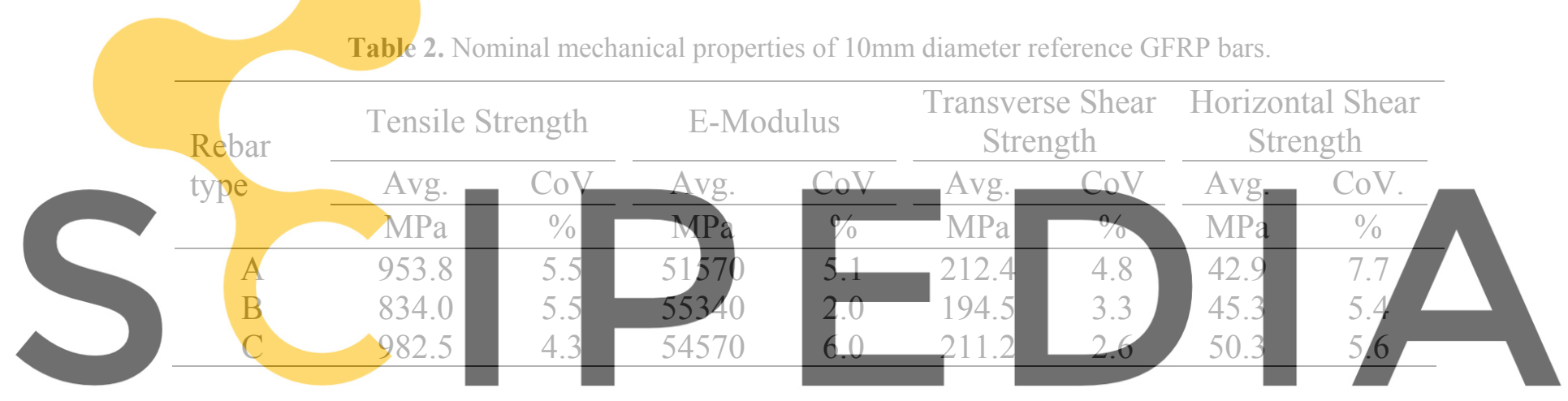

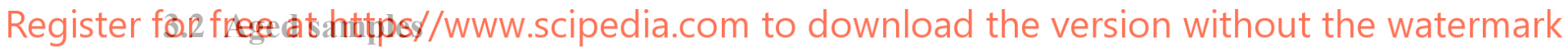

After being exposed to high pH seawater solution for 45, 90 and 180 days, the aged samples were tested, and the results obtained for each of the four mechanical properties were compared to the benchmark values obtained from the unaged specimens, to obtain the retention over time, as shown in Figure 3,4 and 5.

For all the rebar types, the tensile strength was the most affected property with a reduction of up to $41 \%$ for Type-A, while the tensile capacity for Type B and C decreased $29 \%$ and $20 \%$ respectively. Compared to the literature, Chen et al. (2006) saw higher degradation (about $70 \%$ of degradation after 180 days) when exposing GFRP rebars to the same solution (except they used tab water instead of seawater to mixed with the same proportions of hydroxides). 


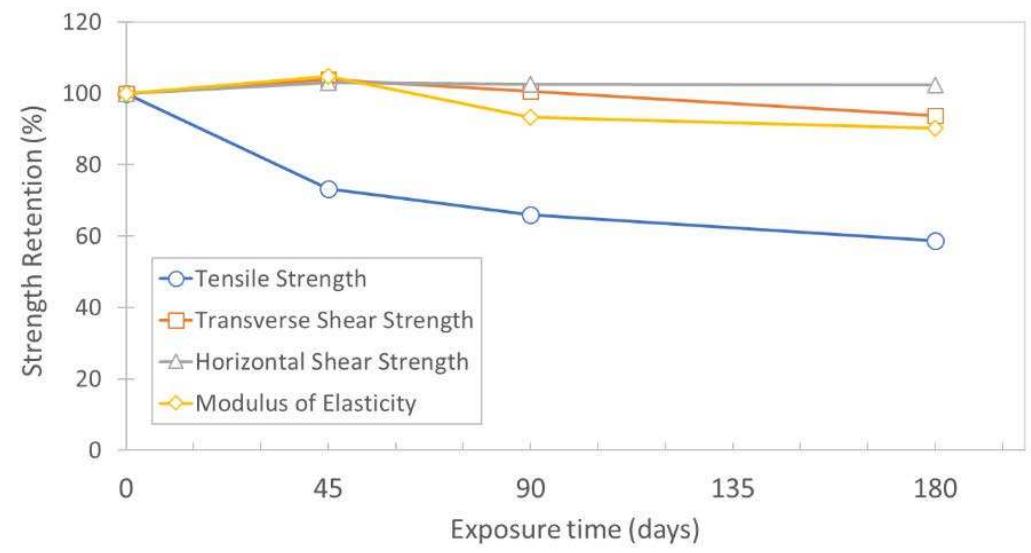

Figure 3. Retention of the tested mechanical properties for Type-A rebars.

This could be due to the lesser development of the GFRP products back in 2006. More recent research conducted by Robert et al. (2013) showed a lower reduction (about 10\%), but the simulated seawater pore solution had a lower $\mathrm{pH}$ (12.15 compared to 13.5 of the current study) and the aging temperature was of $50{ }^{\circ} \mathrm{C}$ instead of $60^{\circ} \mathrm{C}$.
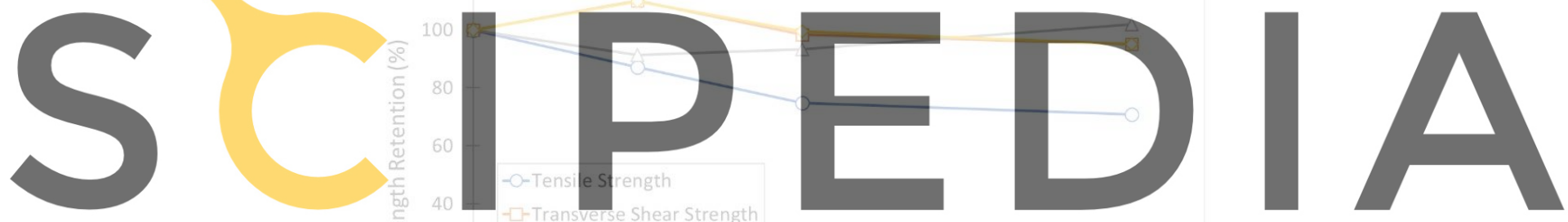

Register for free at https//www.scipedia.com to download the version without the watermark

Exposure time (days)

Figure 4. Retention of the tested mechanical properties for Type-B rebars.

The second most affected property was the modulus of elasticity, even if the reduction was relatively low: between $5 \%$ and $13 \%$. These values are aligned with the data found in the literature (Robert, Cousin and Benmokrane, 2009; Robert and Benmokrane, 2013), where it was seen that that degradation of the modulus was insignificant compared to the reduction of the maximum tensile capacity. It is believed by the authors that a degradation of the fiber and resin interface takes place with the time, which affects the stress transfer between fibers. This reduction is more noticeable at a critical strain (related to the maximum tensile strength) where the decrease in the stress transfer capacity may lead to the inability to activate all the fibers of the cross section of the rebar which will result in higher strains in those fibers that are being engaged. This will then cause failure of individual fibers at an earlier stage, leading to a premature failure of the rebar. However, since the elastic modulus is not related to individual 
or incremental fiber failures but rather to the sum of the elastic strain all along the coupon or rebar gage length, is not that heavily affected.

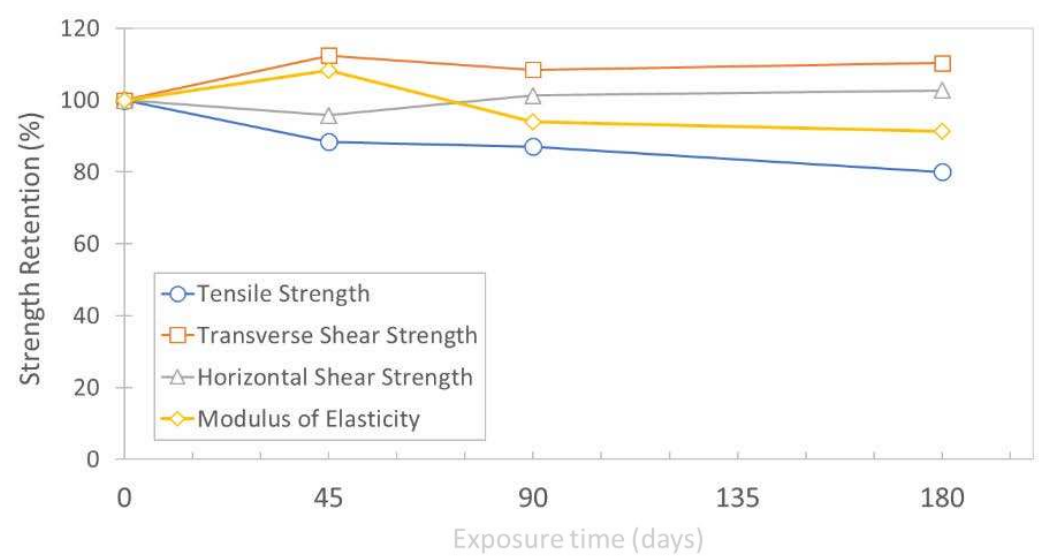

Figure 5. Retention of the tested mechanical properties for Type-C rebars.

Finally, for all the rebar types, the deterioration in terms of transverse and horizontal shear capacity was insignificant. Similar behavior has been reported by Benmokrane et al. (2015), in which GFRP bars (vinyl ester resin matrix with E-glass fibers) where exposed to alkaline solution (pH 12.6 - 13.0) and resulted in horizontal and transverse shear strength reduction of $5 \%$ and $10 \%$, respective even though Wang et al. being aged in a high pH rebars, specially to the the instead of E-CR Glass, being this last one th

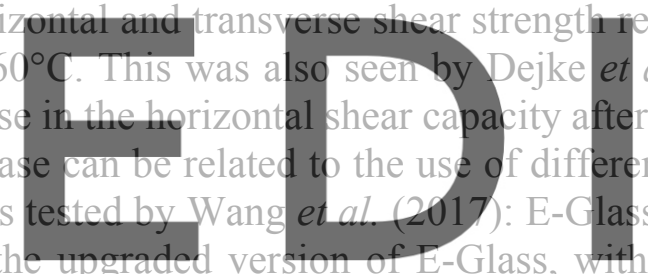
duction of
al. (2007),
the rebars
stypes of
corrosion resistance features.

Register for free at https//www.scipedia.com to download the version without the watermark 4 Conclusions

In this study, the durability of three different GFRP rebar types was assessed after being exposed to a high $\mathrm{pH}$ seawater solution at $60^{\circ} \mathrm{C}$ and different exposure times $(45,90$ and 180 days). Four different mechanical properties were tested: tensile strength, modulus of elasticity, transverse shear strength and horizontal shear strength. It was seen that the resilience after the accelerated exposure depended on the type of rebar. However, for all of them, the tensile strength was the most affected mechanical property, with a reduction of 20 and $41 \%$, followed by the elastic modulus, which decreased between $5 \%$ and $13 \%$. Finally, the horizontal and transverse shear strength capacities were almost unaltered after the aging process. These preliminary results were aligned with the findings reported by other researchers in the literature.

Regarding the significant difference in the reduction between the tensile strength compared to the modulus of elasticity, authors believe that it could be related to the degradation of the fiber and resin interface, which affects the stress transfer between fibers. This reduction is more noticeable at a critical strain (related to the maximum tensile strength) where the decrease in the stress transfer capacity may lead to the inability to activate all the fibers of the cross section of the rebar which will result in higher strains and, therefore, premature failure in those fibers 
that are being engaged. But, since the elastic modulus is not related to individual or incremental fiber failures but rather to the sum of the elastic strain all along the coupon or rebar gage length, is not that heavily affected.

However, the authors of the article acknowledge that more data is needed to confirm these preliminary conclusions. Future research activities include the extension of the aging time and addition of extra exposure temperatures. This data will be then used to model the durability and predict the service life. Finally, it needs to be noted that the durability prediction values should be compared to results obtained from existing structures, to calibrate the durability model.

\section{ORCID}

Alvaro Ruiz Emparanza: https://orcid.org/0000-0001-9781-5107

Carlos N. Morales: https://orcid.org/0000-0003-4279-6839

Antonio Nanni: https://orcid.org/0000-0003-2678-9268

Francisco De Caso: https://orcid.org/0000-0001-5585-7819

References

Chen, Y., Davalos, J. F. and Ray, I. (2006). 'Durability prediction for GFRP reinforcing bars using short-term data of accelerated aging tests', Journal of Composites for Construction. American Society of Civil Engineers, 10(4), pp. $279-286$.

Dejke, V. and Tepfers, R. (2001). 'Durability and service life prediction of GFRP for concrete reinforcement', in Proc., 5th Int. Conf. on Fiber-Reinforced Plastics for Reinforced Concrete Structures (FRPRCS-5). Thomas Telford London, pp. 505-516.

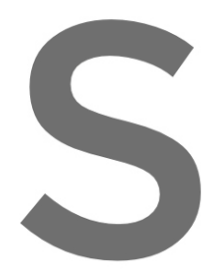

Dong, Z. et al. (2016). 'Bond durabilit term bond strength predic

Nolan, S., Rossini, M. an Transportation Research

Robert, M. and Benmokrane, of GFRP reinforcing bats?

Robert, M., Cousin, P. and Benmokraite.
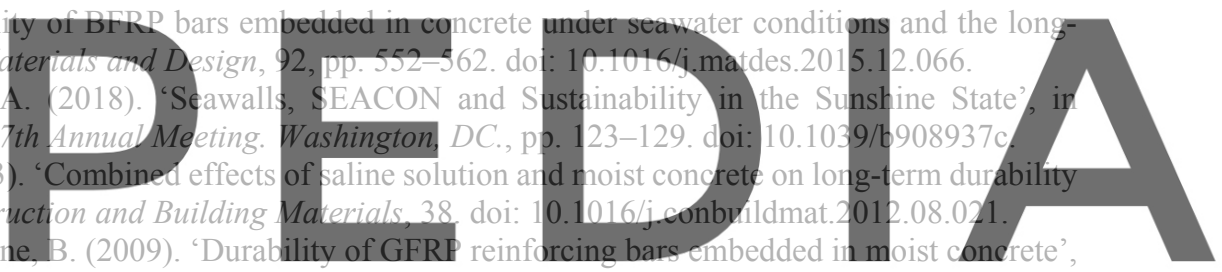
Journal of Composites for Construction. American Society of Civil Engineers, 13(2), pp. 66-73.

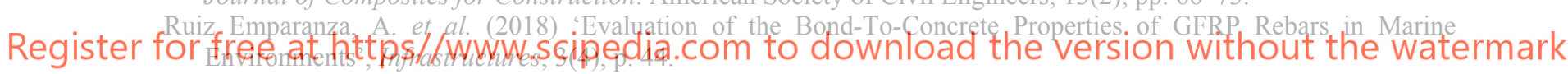

Ruiz Emparanza, A., Kampmann, R. and De Caso Y Basalo, F. (2017). 'State-of-the-Practice of Global Manufacturing of FRP Rebar and Specifications', in ACI Fall Convention. Anaheim, CA.

Wang, Z. and Zhao, X. L., et al. (2017). 'Durability study on interlaminar shear behaviour of basalt-, glass- and carbonfibre reinforced polymer (B/G/CFRP) bars in seawater sea sand concrete environment', Construction and Building Materials, 156, pp. 985-1004. doi: 10.1016/j.conbuildmat.2017.09.045.

Pauling, L. C. (1988). General Chemistry. Dover Publications.

Wang, Z. and Zhao, X.-L., et al. (2017). 'Long-term durability of basalt-and glass-fibre reinforced polymer (BFRP/GFRP) bars in seawater and sea sand concrete environment', Construction and Building Materials. Elsevier, 139, pp. 467-489.

Yan, F. and Lin, Z. (2017). 'Bond durability assessment and long-term degradation prediction for GFRP bars to fiberreinforced concrete under saline solutions', Composite Structures. Elsevier, 161, pp. 393-406.

Grubb, J. A.; Limaye, H. S.; and Kakade, A. M., “Testing pH of Concrete," Concrete International, V. 29, No. 4, Apr. 2007, pp. 78-83.

Benmokrane, B., Elgabbas, F., Ahmed, E. and Cousin, P. (2015). Characterization and Comparative Durability Study of Glass/Vinylester, Basalt/Vinylester, and Basalt/Epoxy FRP Bars. Journal Of Composites For Construction, 19(6), 04015008/1-04015008/12. 